\title{
Haemodynamic Effects of Pericardial Closure after Cardiac
}

\section{Surgery}

\author{
Saurabh KS ${ }^{1}$, Padhy $\mathrm{AK}^{2}$, Kumar $\mathrm{M}^{3}$, Munjal $\mathrm{R}^{4}$, Gupta $\mathrm{A}^{5}$
}

${ }^{1,3,4}$ Senior Resident, Cardiovascular Thoracic Surgery, Vardhaman Mahavir Medical College \& Safdarjung Hospital ${ }^{2}$ Assistant Professor, Cardiovascular Thoracic Surgery, Vardhaman Mahavir Medical College \& Safdarjung Hospital 5HOD, Cardiovascular Thoracic Surgery, Vardhaman Mahavir Medical College \& Safdarjung Hospital

Corresponding author: Padhy AK Department of Cardiothoracic and Vascular Surgery, VMMC and Safdarjung Hospital, New Delhi.

\begin{abstract}
Introduction: Whether pericardial closure should be done or not is still a debated topic. While many studies favour pericardial closure after cardiac surgery, many are still not in favour of the same.

Objective : Objective of this study was to analyse the changes induced by pericardial closure on the haemodynamic of the patient using easily measurable variables.
\end{abstract}

Methods : Data of 30 patients were analysed of which 14 underwent mitral valve replacement, 10 underwent coronary artery bypass grafting and 6 underwent double valve replacement.

Results:

There was statistically significant change in cardiac output $(p<0.01)$, central venous pressure $(p<0.05)$ and left ventricular end diastolic diameter $(p<0.01)$ after pericardial closure. Clinically the pericardial closure was well tolerated.

Conclusion: Despite exhaustive experience, the topic of closing pericardium is still debated. Our study shows that clinically pericardial closure is well tolerated and in return it also safeguards the risks associated with re-do operations.

Keywords: Pericardial closure, Cardiac output, Left ventricular end diastolic diameter, Central venous pressure

\section{Introduction}

In patients who undergo open heart surgery, the pericardium is left open in a credence that it lowers the incidence of cardiac tamponade post-operatively ${ }^{[1]}$. However, many studies are of opinion that for prevention of re-entry entries in re-do cases, pericardial closure lowers its incidence ${ }^{[2-4]}$. In current scenario, the need for re-operation is increasing progressively ${ }^{[5]}$. During re-intervention, the risk of injury to intrathoracic structures primarily the structures lying in the anterior part, particularly the right ventricle and the great vessels are at highest risk of injury if the pericardium was left open in first surgery ${ }^{[6-8]}$.

Also, the closed pericardium is suggested to act as infection barrier in a post-operative case. The bleeding in the postoperative period is mostly extra-pericardial, the pericardial closure decreases the occurrence of tamponade and postpericardiotomy syndrome ${ }^{[9]}$. In two clinical studies, it is demonstrated that pericardial closure essentially reduced the incidence of postoperative cardiac tamponade ${ }^{[2,9]}$.

Still there is an existing controversy about the effects of pericardial closure on cardiac function parameters. Drop in cardiac output ${ }^{[10-12]}$ and blood pressure ${ }^{[13]}$ has been described after pericardial closure. All these studies ${ }^{[10-13]}$ comprised of patients who had undergone coronary artery bypass grafting (CABG), and therefore there was the likelihood of a constrictive effect of pericardial closure on the grafts along with on the heart. Although the pericardium is routinely closed in our institution, per operative re-opening is occasionally necessary for any persistent low arterial blood pressure and low cardiac output.

\section{Methods-}

Retrospectively, the data of Thirty patients ( 12 females and 18 males, Table 1) who underwent open-heart surgery, were included in the study. 14 patients underwent mitral valve replacement with LAA (Left atrial appendage) ligation (either internal or external), 10 patients underwent Coronary Artery Bypass Grafting, while the remaining 6 patients underwent both mitral valve and aortic valve replacement under Cardiopulmonary bypass with cold cardioplegic arrest (Table 2).

Inclusion criteria -

All adult cardiac cases who underwent cardiac surgery using cardiopulmonary bypass. Exclusion criteria -

a) All the patients who underwent off-pump surgeries.

b) All the re-do cases.

c) All cases requiring excision of pericardium (e.g. chronic constrictive pericarditis)

d) All congenital cases.

The data analysis was carried out intra-operatively after the patient was taken off cardiopulmonary bypass and in a stable hemodynamic state with filling pressures identical to preoperative values. The patients were under fentanyl anaesthesia ( $5 \mathrm{mics} / \mathrm{kg}$ ), etomidate $(0.2 \mathrm{mg} / \mathrm{kg})$ and vecuronium $(0.1 \mathrm{mg} / \mathrm{kg})$ for muscle relaxation.

Normo-ventilation was continued with a mechanical ventilator. 
Inotropic agents and/or vasodilators were used as needed. Overfilling of the heart was avoided. Blood was infused to recompense bleeding. Pressure measurements were performed with standard transducers.

Cardiac output was determined by a cardiac output monitor (Edwards Vigileo Monitor, 2012 model). Cardiac output was calculated by attaching the radial arterial line to the cardiac output monitor. Echocardiography was used for the determination of the left ventricular cavity diameter. Ensuing baseline measurements, the pericardiotomy incision was closed with interrupted sutures $2 \mathrm{~cm}$ apart in the way usually used for pericardial closure which avoids undue tension. After a period of 3 to $4 \mathrm{~min}$, the measurements were repeated and Results as described in Table 3. Thereafter the pericardial sutures were removed and the measurements repeated. Then pericardium was closed again in all but one patient. Recovery in all patients was uneventful.

\section{TABLE -1}

\begin{tabular}{|l|c|c|c|c|c|}
\hline & $\begin{array}{c}\text { Number of } \\
\text { patients }\end{array}$ & $\begin{array}{c}\text { Average } \\
\text { age }\end{array}$ & $\begin{array}{c}\text { Average } \\
\text { weight }\end{array}$ & $\begin{array}{c}\text { Average } \\
\text { Height }\end{array}$ & $\begin{array}{c}\text { Average } \\
\text { BSA }\end{array}$ \\
\hline Female & 12 & 39 & 51 & 155 & 1.4 \\
\hline Male & 18 & 40.4 & 53 & 157 & 1.5 \\
\hline
\end{tabular}

TABLE -2

\begin{tabular}{|c|c|}
\hline Procedure & Number of patients \\
\hline MVR + LAA LIGATION & 14 \\
\hline DVR & 06 \\
\hline CABG & 10 \\
\hline
\end{tabular}

\section{TABLE -3}

\begin{tabular}{|l|c|c|c|c|}
\hline \multicolumn{1}{|c|}{ Variable } & $\begin{array}{c}\text { Average Value Before } \\
\text { pericardial closure }\end{array}$ & $\begin{array}{c}\text { Average Value after } \\
\text { pericardial closure }\end{array}$ & Difference (in\%) & $\begin{array}{c}\text { Statistical significance/ } \\
\text { Inference }\end{array}$ \\
\hline SBP $(\mathrm{mmHg})$ & 114 & 111 & 2.6 & Reduced \\
\hline DBP $(\mathrm{mmHg})$ & 66 & 64 & 3.03 & Reduced \\
\hline MBP $(\mathrm{mmHg})$ & 82 & 80 & 10.9 & Reduced \\
\hline $\begin{array}{l}\text { CARDIAC } \\
\text { OUTPUT }\end{array}$ & 5.5 & 4.9 & $20(+)$ & peduced \\
\hline CVP $(\mathrm{cm} \mathrm{H2O})$ & 9.2 & 11.5 & & p<0.01 \\
& & & 2.8 & Increased \\
\hline LVedP $(\mathrm{mmHg})$ & 13.6 & 14.01 & 12.7 & Increased \\
\hline LVEDD $(\mathrm{mm})$ & 50.9 & 44.4 & & p<0.01 \\
& & & & Reduced \\
\hline
\end{tabular}

SBP - Systolic Blood Pressure, DBP - Diastolic Blood Pressure, MBP- Mean Blood Pressure, CVP - Central Venous Pressure,

LVedP- Left ventricular end diastolic pressure, LVEDD- Left ventricular end diastolic diameter
DVR - Double valve replacement,

\section{CABG - Coronary artery bypass grafting}

\section{Results}

Change in heart rate noted was: $86+16$ before closure of the pericardium, $89+17$ after, and $87+18$ beats/min when the pericardium was re-opened. Cardiac rhythm remained unchanged: 20 patients showed sinus rhythm, 4 were in atrial fibrillation, 4 had junctional rhythm, and 2 were on temporary ventricular pacing. Since the wedge pressure may undervalue left ventricular end-diastolic pressure, the left ventricular intracavitary pressure was also noted. Left ventricular end-diastolic cavity diameter verified by echocardiogram in patients revealed a statistically significant $(p<0.01)$ decrease induced by the pericardial closure. Average Mean arterial pressure before pericardial closure was $82 \mathrm{mmHg}$ and after pericardial closure was $80 \mathrm{mmHg}$, average systolic blood pressure before pericardial closure was $114 \mathrm{mmHg}$ and after pericardial closure was $111 \mathrm{mmHg}$, Average diastolic blood pressure before pericardial closure was $66 \mathrm{mmHg}$ and after pericardial closure was $64 \mathrm{mmHg}$. Cardiac output lessened $(p<0.01)$ when the pericardiotomy incision was sutured and returned back to the control level after removing the sutures $(p<0.01)$. Though, the fall in cardiac output was only $10.9 \%$. The pericardial closure increased somewhat $(p<0.05)$ central venous pressure. Clinically, the pericardial closure was well tolerated. 


\section{Discussion -}

In one randomised clinical trial, brief reduction in cardiac index and stroke-work index after pericardial closure has been documented ${ }^{[14]}$. Numerous clinical case series have also stated mild-to-moderate cardiac constriction, drop in cardiac output and a decrease in arterial pressure ensuing primary pericardial closure $[4,9,12,13,15,16]$. The findings are constant due to myocardial oedema and dilatation of both, atria and the right ventricle, with procedures done on cardiopulmonary bypass, in which the normal constraining effect of pericardium is embellished ${ }^{[9]}$. The probable negative effects of pericardial closure on haemodynamic of the patient is transient in nature, and no study shows long term poor outcome. ${ }^{[17]}$.

Hence the common consensus prefers primary closure of pericardium, if feasible ${ }^{[15,18]}$ but it may not be suitable for patients with pre-operative impaired cardiac output or impaired left ventricular function ${ }^{[9,12-17]}$ or in peri-operative patients who entail high preloads to sustain an acceptable cardiac output ${ }^{[14]}$

LV-RV coupling can be modulated by intact pericardium ${ }^{[19]}$. In anesthetized dogs, Kroeker et al. verified that ventricular coupling is ideal when there is $5 \mathrm{mmHg}$ or higher intrapericardial pressure. Under those circumstances, an abrupt decrease in RV filling is attended by an immediate, compensatory rise in LV end-diastolic volume and stroke volume.

Some reports have proposed that pericardial closure after coronary artery bypass grafting might lead to 'kinking' of the bypass grafts or internal mammary artery conduits ${ }^{[4,20-22]}$. While alternate 'tension-free' closure methods have been projected as a solution to this likely problem, these methods merely offer epicardial cover and do not give the true restoration of the pericardial covering.

In our study, the pericardial closure was performed avoiding undue tension. Over distension of the heart was avoided at the end of cardiopulmonary bypass. A control for any change of the base-line values was attained in each patient by recordings taken when the pericardium was re-opened, and the alterations not relating to the pericardial closure could be ruled out. The impact of the pericardium on the left ventricular filling pressure was insignificant.

However, a statistically significant $(p<0.01)$ reduction in the left ventricular end-diastolic cavity diameter happened by the pericardial closure. This imitates smaller left ventricular diastolic volume which can be due to pericardial compression of the ventricle or from limited filling of the ventricle.

The pericardium obstructs the distension of the free wall even more in the thin right ventricle than the left [23] Fascinatingly, the pericardial closure appeared to result in a fall in the left ventricular end-diastolic cavity diameter in patients operated for aortic stenosis also. This supports the concept that the pericardial closure may cause compression of the atria and/or venous return channels to the heart, limiting the filling of the ventricles.

In history, the pericardium was left open because of the discernment that its closure could cause fluid accumulation (including blood) around the heart leading to tamponade ${ }^{[1]}$.

However, this theory is not supported in the literature by any randomized, controlled trials, case-control studies or even case series studies. Recent studies show that closing the pericardium is somewhat protective against cardiac tamponade ${ }^{[2,9]}$ which can be attributed to the less amount of clot formation around the heart by the mediastinal blood ${ }^{[24]}$

Apart from preventing postoperative mediastinal adhesions, closure of the pericardium after cardiac surgery provides a dissection plane between the heart and the retrosternal surface. It has been said that the maintenance of native cardiac geometry plays a vital part in preserving LV function post-operatively ${ }^{[14]}$ while insufficient retrosternal space is a probable risk factor for injury during re-do surgeries $[14,25,26]$.

Post-operative exposure of the heart to pericardial and extra-pericardial blood has been suggested in the development of adhesions ${ }^{[25]}$ and post-pericardiotomy syndrome ${ }^{[9]}$ Inflammation has also been said to play a role in the development of postoperative atrial fibrillation [27-29]. Pericardial closure re-compartmentalizes the mediastinal cavity. The heart can then be ward-off from the blood and its component cytokines along with pro- inflammatory mediators, and also from the wound infections, that may develop during the healing of the sternum

\section{Conclusion -}

In our study, pericardial closure after cardiac surgery which was done using cardiopulmonary bypass significantly decreases left ventricular end-diastolic cavity size and hence somewhat decreases the pump function. Pre-operative patients with normal cardiac index, the $10.9 \%$ decrease in cardiac output was clinically well tolerated.

Despite so much studies and experience, whether the pericardium should be closed after cardiac surgery or not has not yet been answered definitively.

The advantages include protection from adhesions, less chances of injury during re-do cases, re-compartmentalisation of the mediastinum for proper LV function post-operatively, reduced incidence of post-pericardiotomy syndrome, less chances of pericardial tamponade, localisation of bleeding source, improvement in cardiac haemodynamic and some other advantages as discussed before. The potential disadvantages includes risk of graft kinking or compression, 
inflammatory epicardial reactions if pericardial substitutes are used and changes in cardiac output.

\section{Statistical analysis}

The data were analysed with the patients serving as their own controls. Changes found significant in the analysis of variance were isolated using the Statistical tests for comparisons. The level of statistical significance was taken at $p<0.05$.

\section{Limitation of the study: -}

As the sample size was small, the average of all the variables under observation were taken for analysis.

\section{Conflict of interest: - None}

\section{REFERENCES}

1. Gibbon JH. Surgery of the chest. Philadelphia:WBSaunders;1969. p.143.

2. Nandi P, Leung JS, Cheung KL. Closure of pericardium after open heart surgery. A way to prevent postoperative cardiac tamponade. Br Heart J. 1976;38(12):1319-23.

3. Asanza L, Rao G, Voleti C, Hartstein ML, Wisoff BG. Should the pericardium be closed after an open-heart operation? Ann Thorac Surg. 1976;22(6):532-4.

4. Bahn $\mathrm{CH}$, Annest LS, Miyamoto M. Pericardial closure. Ann J Surg. 1986;151(5):612-5.

5. Christakis GT, Ivanov J, Weisel RD, Birnbaum PL, David TE, Salerno TA. The changing pattern of coronary artery bypass surgery. Circulation. 1989;80(3 Pt 1):I151- 61

6. Macmanus Q, Okies JE, Phillips SJ, Starr A. Surgical considerations in patients undergoing repeat median sternotomy. J Thorac Cardiovasc Surg. 1975;69(1):138-43.

7. Loop FD. Catastrophic hemorrhage during sternal reentry. Ann Thorac Surg. 1984;37(4):271-2.

8. Dobell AR, Jain AK. Catastrophic hemorrhage during redo sternotomy. Ann Thorac Surg. 1984;37(4):273-8.

9. Cunningham Jr JN, Spencer FC, Zeff R, Williams CD, Cukingham R, Mullin M. Influence of primary closure of the pericardium after open-heart surgery on the frequence of tamponade, postpericardiotomy syndrome, and pulmonary complications. J Thorac Cardiovasc Surg 1975; 70: 119-125.

10. Frist WH, Daughters GT, Mead CW, Derby GC, Schwarzkopf A, Miller DC. Pericardial closure adversely affects early 1985;72(Suppl 3):1301

11. Daughters GT, Mcad CW, Alderman EL, Derby GC, Schwarzkopf A, Miller DC. Effects of the pericardium on LV diastolic filling in man early after cardiac surgery [Abstract]. Circulation 1985;72(Suppl 3):411
12. Jarvinen A, Peltola K, Rasanen J, Heikkila J. Immediate haemodynamic effects of pericardial closure after open heart surgery. Scand J Thorac Cardiovasc Surg 1987;21:1314.

13. Damen J, Bolton DT. Acute haemodynamic effects of pericardial closure in man. Acta Anaesthesiol S c a d 1989;33:207-9

14. Rao V, Komeda M, Weisel RD, Cohen G, Borger MA, David TE. Should the pericardium be closed routinely after heart operations? Ann. Thorac. Surg. 67(2), 484-488 (1999).

15. Daughters GT, Frist WH, Alderman EL, Derby GC, Ingels NB Jr, Miller DC. Effects of the pericardium on left ventricular diastolic filling and systolic performance early after cardiac operations. J. Thorac. Cardiovasc. Surg. 104(4), 1084-1091 (1992).

16. Hunter S, Smith GH, Angelini GD. Adverse hemodynamic effects of pericardial closure soon after open heart operation. Ann. Thorac. Surg. 53(3), 425-429 (1992).

17. Bittar MN, Barnard JB, Khasati N, Richardson S. Should the pericardium be closed in patients undergoing cardiac surgery? Interact. Cardiovasc. Thorac. Surg. 4(2), 151-155 (2005).

18. Raja SG. Comment to: should the pericardium be closed in patients undergoing cardiac surgery? Interact Cardiovasc. Thorac. Surg. 4(2), 155 (2005).

19. Kroeker CA, Shrive NG, Belenkie I, Tyberg JV. Pericardium modulates left and right ventricular stroke volumes to compensate for sudden changes in atrial volume. Am. J. Physiol. Heart Circ. Physiol. 284(6), H2247-H2254 (2003).

20. Bhatnagar G, Fremes SE, Christakis GT, Goldman BS. Early results using an ePTFE membrane for pericardial closure following coronary bypass grafting. J. Card. Surg.13(3), 190-193 (1998).

21. Li JY, Chen YS, Wu SJ, Hu PY. Modified pericardial closure to protect internal mammary artery grafts in coronary artery bypass. Thorac. Cardiovasc. Surg. 50(3), 182-183 (2002)

22. Zapolanski A, Fishman NH, Bronstein MN, Ellertson DG O'Connell TJ, Siegel S. Modified pericardial closure to protect cardiovascular structures during sternal reentry. Ann. Thorac. Surg. 50(4), 665-666 (1990)

23. Shirato K, Kanazawa M, Ishikawa K, Nakajima T, Takishima T. The effect of pericardium on the diastolic properties of the heart. Experimental studies on volume load and on acute ischemia in open chest dogs. Jap Circ J 1982; 46: 113-123

24. Spodick DH. The Pericardium: A Comprehensive Textbook Marcel Dekker,NY, USA, 387 (1997). 
25. Elahi M, Dhannapuneni R, Firmin R, Hickey M. Direct complications of repeat median sternotomy in adults. Asian Cardiovasc. Thorac. Ann. 13(2), 135-138 (2005).

26. Lahtinen J, Satta J, Lähde S et al. Computed tomographic evaluation of retrosternal adhesions after pericardial substitution. Ann. Thorac. Surg. 66(4), 1264-1268 (1998).

27. Anselmi A, Possati G, Gaudino M. Postoperative inflammatory reaction and atrial fibrillation: simple correlation or causation? Ann. Thorac. Surg. 88(1),326333 (2009).

28. Boos CJ, Anderson RA, Lip GY. Is atrial fibrillation an inflammatory disorder? Eur. Heart J. 27(2), 136-149 (2006)

29. Tselentakis EV, Woodford E, Chandy J, Gaudette GR, Saltman AE. Inflammation effects on the electrical properties of atrial tissue and inducibility of postoperative atrial fibrillation. J. Surg. Res. 135(1), 68-75 (2006).

How to cite this article : Saurabh KS, Padhy AK, Kumar M,

Munjal R, Gupta A Haemodynamic Effects of Pericardial Closure after Cardiac Surgery. Perspectives in Medical Research 2020; 8(1):81-85

Sources of Support: Nil, Conflict of interest: None declared 